\title{
Whitening Effect of an Active Ingredient from Fresh Peral
}

\author{
Anquan Yang ${ }^{13, a}$, Jing Wang ${ }^{13, b^{*}}$, and Lihua Zhang ${ }^{23, c}$ \\ ${ }^{1}$ Zhejiang Freshwater Pearl Processing Engineering Technology Research Center, Deqing, \\ Zhejiang, China, 313200; \\ 2 Zhejiang Osmun Special Cosmetic Co. Ltd, Deqing, Zhejiang, China, 313200; \\ ${ }^{3}$ Zhejiang Osmum Biological Co., LTD, Deqing, Zhejiang, China, 313200 \\ aosmbiotech@163.com, bosmunrd@163.com, 'czhanglh@osm.com.cn
}

\begin{abstract}
Keywords: Ingredient, fresh pearl, whitening effect
Abstract: OBJECTIVE To indent the function of an active ingredient from fresh pearl. METHODS Pearl extract in different concentrations were added into the 96-well plates, which contained B16 melanoma cell. The cell viability, tyrosinase activity and melanin biosynthesis of the B16 melanoma cell were measured. RESULTS The effect of pearl extract on cell viability was better than that of arbutin and alpha hydroxy acid, for example, the value of cell viability conducted by $40 \mathrm{mg} / \mathrm{L}$ pearl extract was $88.83 \pm 2.69 \%$, similar to the $10 \mathrm{mg} / \mathrm{L}$ of arbutin and higher than that of alpha hydroxy acid with the same concentration. In terms of melanin biosynthesis, pearl extract could significantly inhibit the formation of melanin. In addition, half amount of tyrosinase could be inactived by $80 \mathrm{mg} / \mathrm{L}$ pearl extract. CONCLUSION Pearl extract is of high security, and has significant whitening effect, and can be used as new whitening raw materials.
\end{abstract}

\section{Introduction}

Skin whitening is one of the most important effects of skin care. Developments and applications of skin whitening agent promote the research of skin whitening mechanism. Currently, inhibition of skin melanin was found to be the crucial part. Melanin is induced by oxidation of tyrosine by tyrosinase, with various conditions, different oxides are formed, including dopa, dopaquinone, dopachrome, 5,6-Dihydroxy-1H-indole, indole-5,6-dione, and ultimately pigment granules. It was found early by Japanese researchers that, ultraviolet radiation stimulates the proliferation and cellular differentiation of melanoma cell, and improves tyrosinase activity, and finally facilitate the melanin biosynthesis. The inhibition of melanin can be divided in two parts, reducing the activity of tyrosinase and proliferation. In addition, tyrosine is oxidized with involvement of free radicals. Recombinant polypeptide of fibronectin $\mathrm{CH} 50$ was confirmed to reduce the invasiveness and proliferation of B16 melanoma cell.

Pearl was literate in an ancient book kaibao bencao as a medicine, it has tranquilizing effect, heat-clearing and yin-nourishing, promotes good eyesight and detoxify, and heals wounds. With the development of manual pearl (fresh water) and processing methods, pearl is used not only as jewelry, but also functional material to protect from myopia and aging, heal wounds and Cosmetology. Pearl was also proved to have protection on skin cells and have anti-inflammatory and antioxidant effect by Qian and Zhou. The proteins in pearl was considered to related to the functions, but barely proved in literatures. The objective of this research is to investigate the effect of pearl extract on melanoma cell and tyrosinase. The inhibition of melanin by pearl extract is proved by the two parts mentioned previously.

\section{Materials and methods}

\section{Materials}

Freeze-dried pearl extract was provided by Zhejiang Osm Group Deqing Bio-tech Co.Ltd, mainly containing pearl peptide. B16 melanoma cell was bought from Shanghai Institute of Biochemistry and Cell Biology.

Fetal calf serum FBS, $0.25 \%$ pancreatic enzymes (with $0.02 \%$ EDTA) and PBS buffer solution $(\mathrm{pH}=7.4)$ are from Hangzhou Keyi Bio-tech Co. Ltd. Culture medium (RPMI-1640), MTT, Triton 
X-100 were bought from Sigma. DMSO is from Shanghai Chemical Reagent Co. and Triton X-100 is from Merck. Microplate reader (Bio-Rad US). Carbon dioxide incubator

\section{Methods}

Cell culture ${ }^{[1]}$. B16 melanoma cell in logarithmic growth status was rinsed by PBS buffer solution (Hangzhou Keyi Bio-tech Co. Ltd.), and digested using 0.25\% pancreatic enzymes (Hangzhou Keyi Bio-tech Co. Ltd.), then counted the cell population. The passage cells were diluted to $5 \times 10^{4}$ $\mathrm{CFU} / \mathrm{mL}$ by using $10 \%$ Fetal calf serum (Hangzhou Keyi Bio-tech Co. Ltd.), to make a single cell suspension. The suspension was added into 96-well plates, $200 \mu \mathrm{L}$ for each, incubated in the condition of $37{ }^{\circ} \mathrm{C}$ and $5 \% \mathrm{CO}_{2}$ for $24 \mathrm{~h}$, then the supernate was discarded and the solid was rinsed by PBS once again. Different concentrations of pearl extract $(10,20,40,80,10 \mathrm{mg} / \mathrm{L})$ and $160 \mu \mathrm{L}$ of PBS were added in the solid respectively, then incubated in $37^{\circ} \mathrm{C}$ and $5 \% \mathrm{CO}_{2}$ for $24 \mathrm{~h}$. The control group was free of pearl extract, and the blank group only contained $200 \mu \mathrm{L}$ of PBS.

MTT method ${ }^{[2]}$. After $24 \mathrm{~h}$ of incubation, $10 \mu \mathrm{L}$ of $5 \mathrm{~g} / \mathrm{L}$ MTT (Sigma, US) was add in every well, the supernatant was discarded after $4 \mathrm{~h}$, then add $100 \mu \mathrm{L}$ of DMSO (Shanghai Chemical Reagent Co.), vibrated for $10 \mathrm{~min}$, and the absorption value was detected by a microplate reader (Bio-Rad, US) at $490 \mathrm{~nm}$. The survival rate of melanoma cells was calculated by the following equation 1 .

$$
\text { Survival rate }=\left(1-\frac{\text { Average absorption }}{\text { Average absorption of control }}\right) \times 100 \%
$$

Microscopic inspection. The culture medium was removed after $24 \mathrm{~h}$ and $48 \mathrm{~h}$ of incubation, the cells were washed 2 times by using PBS buffer, stabilized by $4 \%$ of methanal for 15 min, then rinsed by deionized water for 3 times and added $0.1 \%$ of dopa solution to dye for $3.5 \mathrm{~h}$, then the cells were washed by PBS and deionized water again. After that, the cells were observed using a microscope at 100 times of magnification.

Content of melanoma [3]. To detect the content of melanoma in cells, after $24 \mathrm{~h}$ of incubation, the cells were rinsed by PBS for 2 times, added in $1 \mathrm{~mol} / \mathrm{L}$ of $\mathrm{NaOH}$, and diluted to $0.2 \mathrm{~mol} / \mathrm{L}$ by double-distilled water, then bathed in $80^{\circ} \mathrm{C}$ for $1 \mathrm{~h}$ to dissolve the cells and detected the absorption by the microplate reader at $400 \mathrm{~nm}$. The relative content of melanoma was calculated by the following equation 2 and 3.

$$
\begin{array}{r}
\text { Content of melanoma }=\frac{\text { Absorption of sample }}{\text { Absorption of control }} \times 100 \% \\
\text { The relative content of melanoma }=\frac{\text { Content of melanoma }}{\text { survival rate }}
\end{array}
$$

Activation of tyrosinase ${ }^{[4]}$. The concentration of melanoma cells suspension was adjusted to $1 \times 10^{5} / \mathrm{mL}$ and added into the 96 -well plate renewed the medium after $24 \mathrm{~h}$, and added $100 \mu \mathrm{L}$ of pearl extract at different concentrations $(10-100 \mathrm{mg} / \mathrm{L})$. After $48 \mathrm{~h}$ of incubation, the supernatant was discarded and the cells were washed by PBS buffer for 2 times, add 1\% of Triton X-100 to dissociate the cells and freeze in $-80^{\circ} \mathrm{C}$ for $1 \mathrm{~h}$, then melted at room temperature to release the tyrosinase. After a pre-thermal treatment of $37^{\circ} \mathrm{C}, 1 \%$ of dopa solution was added and kept for $1 \mathrm{~h}$, then the absorption was detected at $490 \mathrm{~nm}$, the activation of tyrosinase was calculated by the following equation 4 .

$$
\text { Activation of tyrosinase }=\frac{\text { Absorption of sample I Absorption of control }}{\text { Absorption of control }} \times 100 \%
$$

Statistical method. The data was presented by the combination of average and standard deviation, the variance analysis was finished by SPSS 18.0.

\section{Results and conclusion}

\section{Effects on the B16 cell}

Cell viability. The stimulation of cosmetic materials on body skin ought to be investigated before used as ingredients. Figure 1 compared the effects of pearl extract, arbutin, and alpha hydroxy acid on the viability of skin cells. Higher concentration of the samples induced more impact on cell viability. The pearl extract has the least influence, and the alpha hydroxy acid has the biggest 
influence. In low concentrations, the skin cells using pearl extract kept relatively higher viability, and the one using alpha hydroxy acid lose more cell viability. Arbutin in low concentration promoted the reproduce of skin cell, with higher concentration, it gradually had negative influence. Pearl extract with $40 \mathrm{mg} / \mathrm{L}$ resulted in higher population of B16 cell than $10 \mathrm{mg} / \mathrm{L}$ of arbutin and alpha hydroxy acid, which means pearl extract, has safety advantages over arbutin and alpha hydroxy acid.

Table 1 Effects of pearl extract on the B16 cell survival rate

\begin{tabular}{cccc}
\hline Concentration, mg/L & Pearl extract & Arbutin & Alpha hydroxy acid \\
\hline 10 & $96.22 \pm 3.13 \mathrm{ab}$ & $88.72 \pm 1.42 \mathrm{~b}$ & $71.00 \pm 9.55 \mathrm{~b}$ \\
15 & $93.35 \pm 2.48 \mathrm{bc}$ & $80.38 \pm 5.48 \mathrm{bc}$ & $69.71 \pm 6.18 \mathrm{~b}$ \\
20 & $92.34 \pm 0.92 \mathrm{bc}$ & $71.00 \pm 3.55 \mathrm{~cd}$ & $58.28 \pm 7.81 \mathrm{bc}$ \\
40 & $88.83 \pm 2.69 \mathrm{bcd}$ & $65.21 \pm 1.56 \mathrm{~d}$ & $51.00 \pm 4.67 \mathrm{c}$ \\
80 & $87.92 \pm 5.64 \mathrm{bcd}$ & $57.24 \pm 2.78 \mathrm{e}$ & $39.71 \pm 6.79 \mathrm{~d}$ \\
100 & $86.00 \pm 0.74 \mathrm{~d}$ & $48.24 \pm 5.15 \mathrm{f}$ & $28.28 \pm 6.21 \mathrm{~d}$ \\
\hline
\end{tabular}

Microscopic inspection. Figure 1 shows the effect of pearl extract on B16 melanoma cell. Figure 1(a) and figure 1(b) presented that pearl extract reduces pigmentation after $24 \mathrm{~h}$ of cultivation as compared with control. After $48 \mathrm{~h}$ of cultivation, the increasing population that using pearl extract was less than that of control. In general, pearl extract can effectively inhibit the reproduce of B16 melanoma cell and pigmentation.

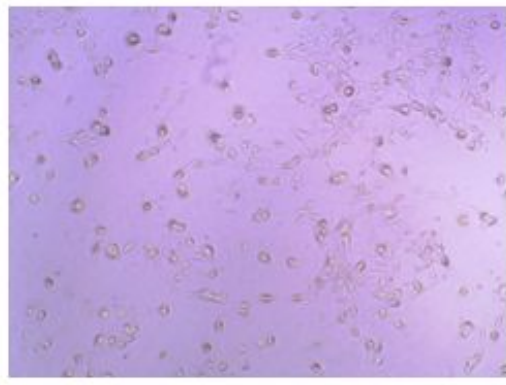

a

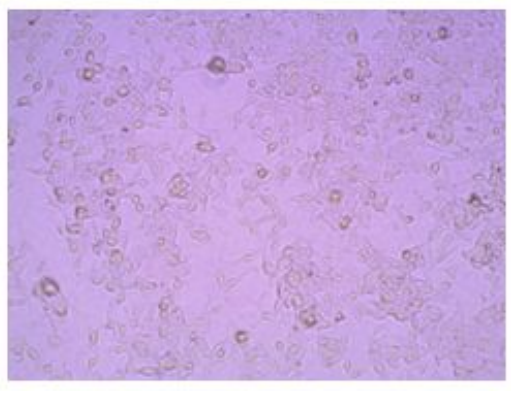

$\mathrm{c}$

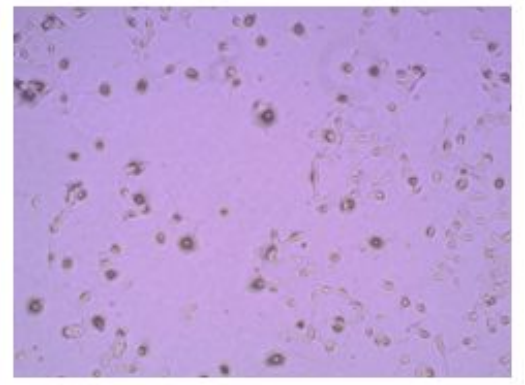

$\mathrm{b}$

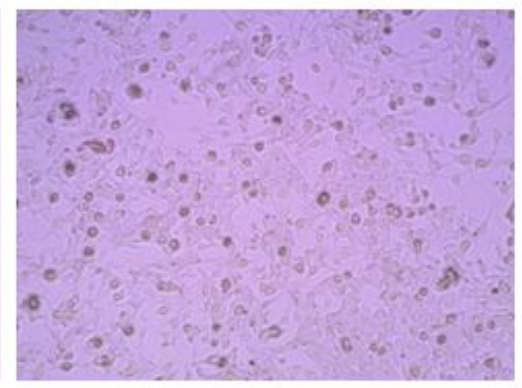

d

Fig.1 Effect of pearl extract on B16 melanoma cell

(a.24h , 40mg/L pearl extract; b 24h, blank; c. 48h, 40mg/L pearl extract; b. 48h Blank)

\section{Effect of pearl extract on the content of melanoma}

To compare the effects of three samples on the intracellular melanoma, we divided the relative melanoma content with the survival rate, which was showed in figure 2 . It indicated that only pearl extract was capable to reduce the melanoma content in living cells significantly. The arbutin and alpha hydroxyl acid reduce the total melanoma content by destroying the cells. Obviously, pearl extract was better in both protection of skin cells and inhibition of melanoma. 


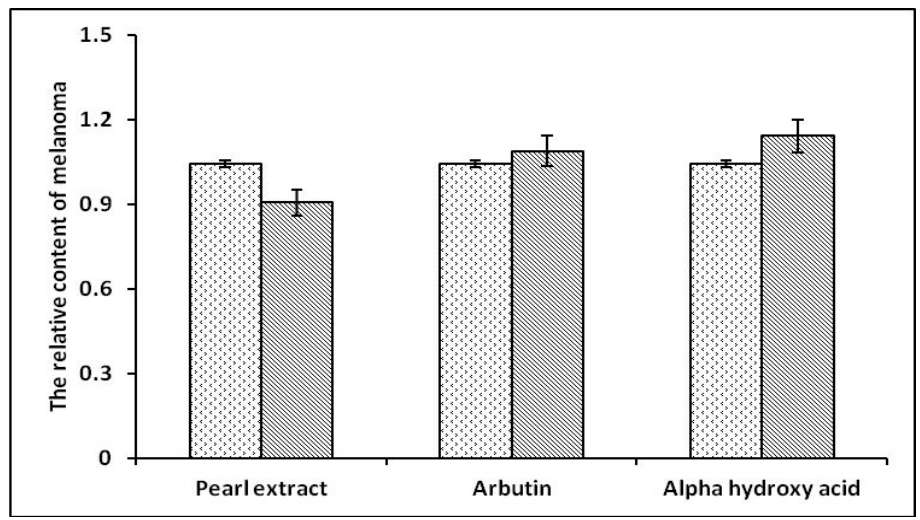

Fig.2 Effect of pearl extract on the content of melanoma

\section{Effect of pearl extract on the tyrosinase activity}

Pearl extract was proved to have significant inhibition effect on tyrosinase activity. With increasing of concentration of pearl extract, tyrosinase activity decreased from $87.2 \%$ to $41.36 \%$. Half of the activity of tyrosinase was inhibited by $80 \mathrm{mg} / \mathrm{L}$ of pearl extract. However, $100 \mathrm{mg} / \mathrm{L}$ of arbutin can only reduce about $30 \%$ of the activity.

Table 2 Effect of pearl extract on the tyrosinase activity

\begin{tabular}{ccc}
\hline Concentration mg/L & Pearl Extract & Arbutin \\
\hline 10 & $79.22 \pm 6.26 \mathrm{a}$ & $89.67 \pm 2.62 \mathrm{a}$ \\
20 & $70.34 \pm 1.84 \mathrm{~b}$ & $84.91 \pm 7.58 \mathrm{ab}$ \\
40 & $61.83 \pm 5.38 \mathrm{c}$ & $79.91 \pm 6.64 \mathrm{bc}$ \\
80 & $50.92 \pm 10.22 \mathrm{~d}$ & $76.61 \pm 6.26 \mathrm{bc}$ \\
100 & $41.36 \pm 4.88 \mathrm{~d}$ & $69.11 \pm 4.26 \mathrm{c}$ \\
\hline
\end{tabular}

\section{Conclusion}

The effects of pearl extract on reproduce of B16 melanoma cell, pigmentation and tyrosinase activity were investigated in this research. Compared with arbutin and alpha hydroxy acid, $40 \mathrm{mg} / \mathrm{L}$ of pearl extract resulted in higher survival rate of skin cell than $10 \mathrm{mg} / \mathrm{L}$ of arbutin and hydroxyl. The research indicated that pearl extract had better inhibition of pigmentation and reproduce, which was also proved by the microscopic examination. Pearl extract was demonstrated to reduce more tyrosinase activity than arbutin and alpha hydroxy acid. In general, pearl extract was proved to be a functional material that can be used in cosmetics. In the future, more clinical tests are needed to verify the effect of pearl extract.

\section{References}

[1]Yanyan Kang, Meiying Zhang, Shaojing Xing, Sheng Xiong, Yifei Wang, and Yanmei Zhu. Toxicity and lightening effects of several natural active products on melanocytes. China surfactant detergent \&cosmetics. 2005, 35(6): 361-369.(In Chinese)

[2]Yajun Yang, Li Lin, Jiayi Ding, Jun Liu, and Yan Chen. Research in cryobiology on the effectiveness of natural active products. China surfactant detergent \&cosmetics, 2002, 32(3): 19-21. (In Chinese)

[3]Mu Zhang, Zemin Yan, Shaojuan Zhu, Tingzhi Fu, and Mingxing Duan. Research on the whitening effectiveness of several traditional chineses medicines. Flavour fragrance cosmetics,2009,1:33-36. (In Chinese)

[4]Xiaolu Chen, Yingna Bi, Chengping Liu, Xuefen Su, and Jian Wang。Effects of Cynanchi Atrati Radix et Rhizoma Percutaneous Fluid on B16 Melanoma Cell. Chinese journal of experimental traditional medical formulae [J]. 2014, 20(12): 193-196. (In Chinese) 